\title{
Body Maps: A Generative Tool for Soma-based Design
}

\author{
Karen Anne Cochrane \\ Carleton University, \\ Ottawa, ON, Canada
}

karen.cochrane@carleton.ca

\section{Kristina Mah}

Affective Interactions Lab, School of

Architecture, Design and Planning,

The University of Sydney,

Sydney, Australia

kristina.mah@sydney.edu.au
Madeline Balaam

Media Technology and Interaction Design, EECS

KTH Royal Institute of Technology

Stockholm, Sweden

balaam@kth.se

\section{ABSTRACT}

Body maps are visual documents, where somatic experiences can be drawn onto a graphical representation of an outline of the human body. They hold the ability to capture complex and non-explicit emotions and somatic felt sensations, elaborating narratives that cannot be simply spoken. We present an illustrative example of "how-to" complete a body map, together with four case studies that provide examples of using body maps in design research. We identify five uses of body maps as generative tools for soma-based design, ranging from sampling bodily experience, heightening bodily self-awareness, understanding changing bodily experience over time, identifying patterns of bodily experience, and transferring somatic experiential qualities into physical designs. The different requirements for scaffolding the use of body maps in

Permission to make digital or hard copies of part or all of this work for personal or classroom use is granted without fee provided that copies are not made or distributed for profit or commercial advantage and that copies bear this notice and the full citation on the first page. Copyrights for third-party components of this work must be honored. For all other uses, contact the Owner/Author.

TEI '22, February 13-16, 2022, Daejeon, Republic of Korea (c) 2022 Copyright is held by the owner/author(s).

ACM ISBN 978-1-4503-9147-4/22/02.

https://doi.org/10.1145/3490149.3502262
Naseem Admadpour

Affective Interactions Lab, School of Architecture, Design and Planning,

The University of Sydney,

Sydney, Australia

naseem.admadpour@sydney.edu.au
Anna Ståhl

Digital Systems

RISE, Research Institutes of Sweden

Stockholm, Sweden

anna.stahl@ri.se
Claudia Núñez-Pacheco

KTH Royal Institute of Technology

Stockholm, Sweden

cnunezpacheco@gmail.com

user-centred design versus first-person autobiographical design research are discussed. We provide this Pictorial as a resource for designers and researchers who wish to integrate body maps into their practice.

\section{Authors Keywords}

Design, Research, Body map, Design Tool, Embodied experiences, HCI, Somatic practices

\section{CSS Concepts}

-Human-centered computing Interaction design Empirical studies in interaction design •Humancentered computing Interaction design $\sim$ Interaction design process and methods $\sim$ User centered design

\section{INTRODUCTION}

Currently, we are witnessing an increase in somabased designs and approaches [16, 24], leading to the development of wearables, and tangible and embodied interactions that place the body at the center of design processes. These systems render experiences of sometimes tacit bodily experiences, which can be hard to describe in words. Body maps are tools used to express and document such somatic experiences. A body map is a visual document graphically outlining the human body from different views (front, back, side and others), highlighting the whole soma or specific areas of

\section{Lian Loke}

Affective Interactions Lab, School of Architecture, Design and Planning, The University of Sydney,

Sydney, Australia lian.loke@sydney.edu.au

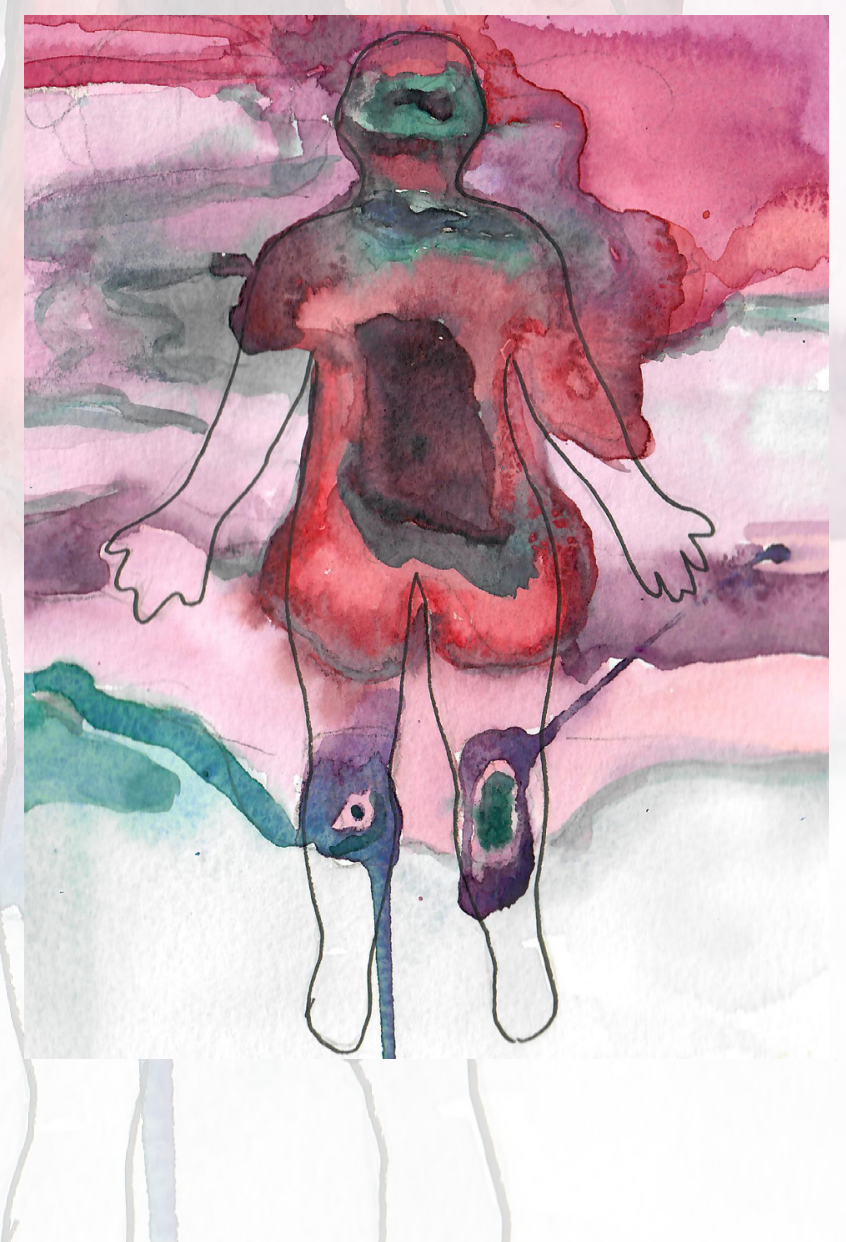


interest. Body maps can be freely adapted to fit the user's specific needs and interests in representing a specific somatic experience. They are typically completed with drawings, scribblings and symbols emerging from the person's intuition, which are related to their personal experience [12]. Body maps can be completed with coloured pens, paint, images from magazines, fabric, etc. They hold the ability to capture complex and non-explicit emotions and felt sensations, elaborating narratives that cannot be simply spoken [12]. This tool has its origin in the arts [10], but the artistic quality is not the focus in the creation of body maps within human-computer interaction (HCI) and design. Body maps function as projective tools [28], which means that those who complete them, project or extend their embodiment, mapping out what occurs in their self-awareness.

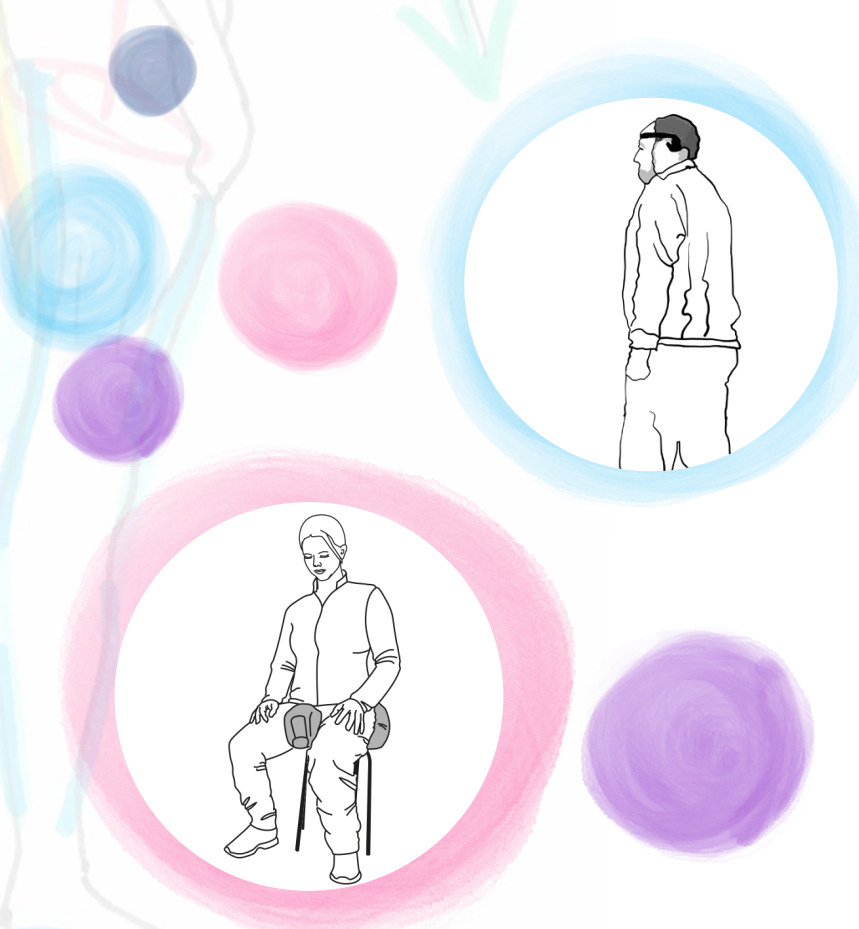

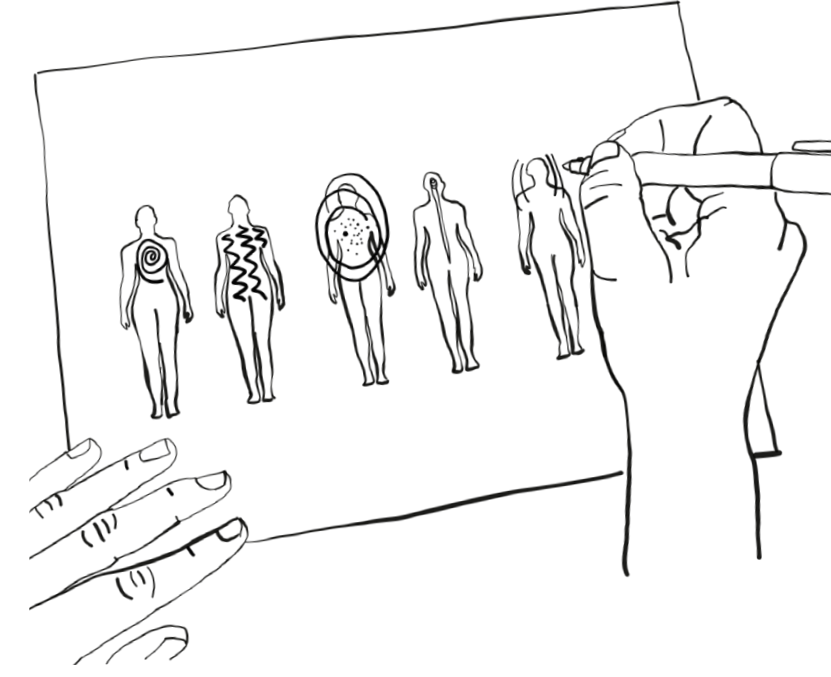

Body maps are used in other fields than arts, such as social work, health, and wellbeing $[6,12,18]$ and have been adopted by HCI. With a few exceptions [18, 29, 30, 36], body mapping is the approach that has been used the most to capture emotions and felt sensations beyond words and standardized categories in HCI [15]. The application of body maps is used to prompt conversations $[5,20]$, design experiences $[26,37]$ and develop technology-assisted somatic experiences [34, 40].

However, there are still limited reports on the generative power of body maps, how they can enable the creation of outcomes for research and practice, including new design ideas and knowledge. To fill this research gap, we present a practical how-to-do body mapping and bring forth four case studies from the authors that make use of body maps: The Pelvic Chair; Understanding the Experience of a Group Walking Meditation Exercise; Self-Observation of Compassion Cultivation for HCI; and The Felt-Sense Archetype Method. Here, we illustrate how the body maps become a generative tool in opening up many different forms of making use of the captured inner somatic experiences. These example cases can inform and inspire other designers that are working with felt experiences in how to apply and make use of body maps. This is not a strict method, but an in- tuitive, open-ended way to project, capture, reflect and document somatic experiences in the moment to later become generative in the different stages of a design research process. Finally, we reflect on different uses of body maps and discuss whose bodily data is recorded. In sum, our contribution is twofold: (1) we offer an illustrative example of a "how-to" approach of body mapping, and (2) through the four case studies we illustrate the body maps generative power by identifying five different uses of body maps from the case studies: Sample somatic experience; Foster heightened self-awareness and inner dialogue; Understand the dynamic, evolving experience of the body over time; Identify patterns of bodily experience; and Transfer bodily experiences via experiential qualities into a physical design.

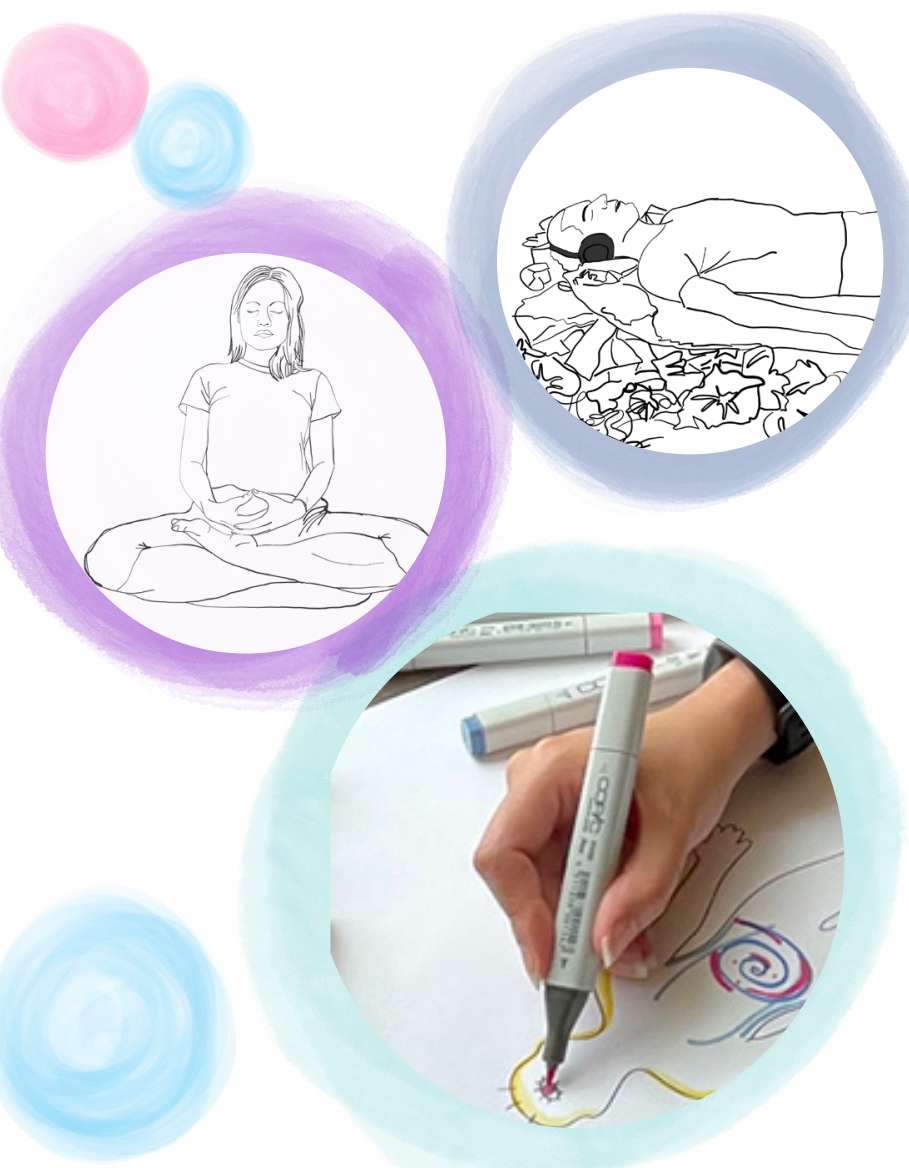




\section{HOW TO}

COMPLETE A BODY MAP
The process to complete a body map is primarily intuitive and open-ended. There are no specific rules, no right or wrong for how to go about it. The goal is not to make the outcome look good, it is not art. Below we offer some suggestions, based on our own experiences, on how to get started.

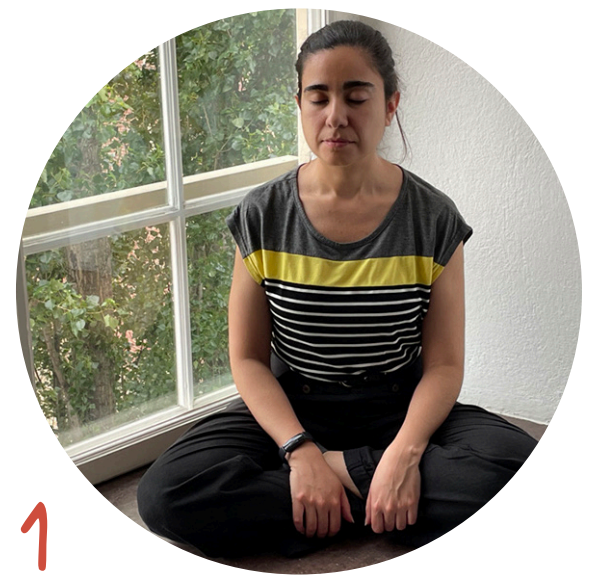

Let us begin with a sample exercise: sit comfortably and close your eyes for a few minutes. Try to become aware of your different body parts, from head to toe, and make a mental note on how these are feeling. Consider, for instance, if you are feeling relaxed or a bittense. Or if there is any trace of pain or discomfort. You can also note if there are some positive sensations. Did you experience any predominant emotions during the exercise? Where in your body did you feel them?

\section{MAKE IT}

\section{FIT YOUR RESEARCH NEEDS}

The variations in how body maps are used may be as many as there are users. So we would like to emphasise that adjusting the body map to fit your needs is one of the most important pieces of advice in how to use a body map. Some researchers use body maps to illustrate participants' somatic experiences before and after engaging in design activities, which helps to capture changed somatic awareness. You may consider including some suggestions of words for your participants, to make their articulation process easier. Some researchers feel restricted by the outline of the body; perhaps you might want to focus on a specific area of the body or free form instead? Sometimes parts of the body stand out in the somatic experience and require more details.

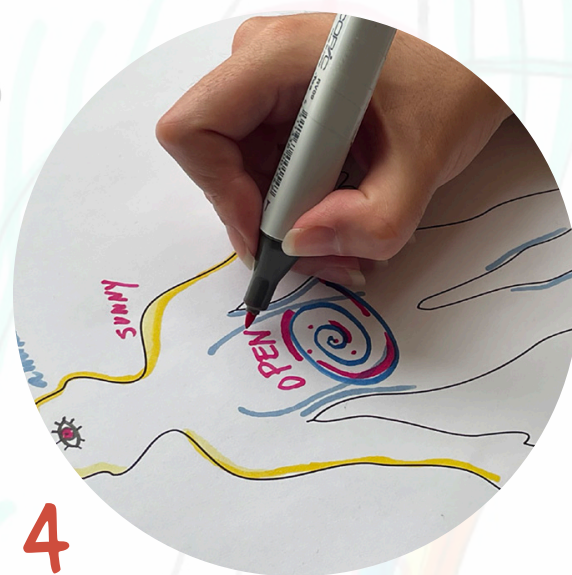

If you find it helpful, you may annotate some key terms next to the body map.
Here you may use coloured pens to draw attention

to the parts of your body that you felt were more symbols to represent sensory information, such as temperature, awareness of the surrounding environment, discomfort, and so on
Oh that was good

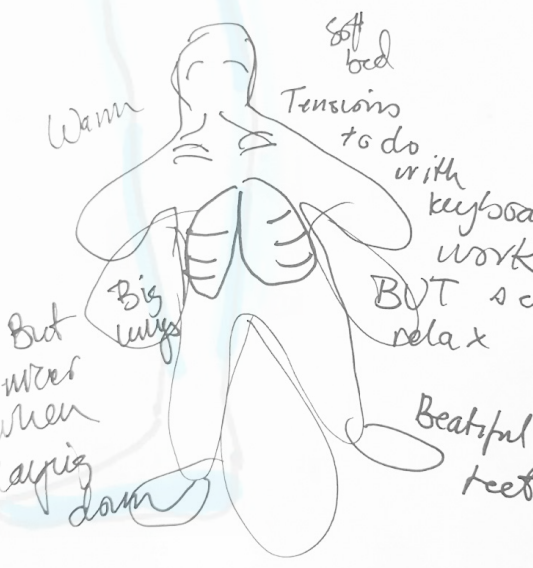




\section{CASE STUDY 1: BODY MAPS AS A TOOL TO} TRANSFER FELT EXPERIENCE INTO DESIGN

This case describes how body maps were used as a guiding tool in a first person perspective throughout the design process of the Pelvic Chair. They were applied to capture the felt experiences in Feldenkrais [11] exercises around the pelvic area. Then the body maps were transferred into articulated experiential qualities [25], these are both to be experienced in the design and be guiding throughout the research-through-design process. In the diagram below, the role the body maps took is illustrated and how these, together with the experiential qualities, were returned to throughout the design process as a way to guide our design decisions and to understand the dynamic, evolving experience of the body over time. Next, this role of the body maps will be shown in detail.

\section{ANCHOR POINT 1:}

tuning into the soma \& body maps

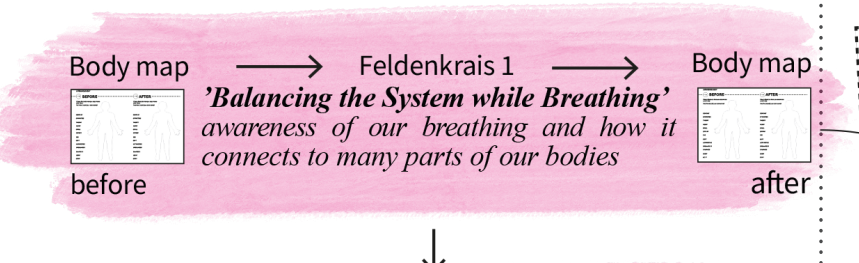

Body map $\longrightarrow$ Feldenkrais $2 \longrightarrow$ Body map 'The Front and Back of the Pelvic Floor' awareness of front and back, how they connect, can be moved separately with help
from surrounding muscles e.g. abdominals

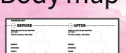

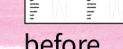

$\downarrow$

Body map $\longrightarrow$ Feldenkrais 3 Sitting on a Chair' moved in connection with other parts of our

before
bodies. Connection with quarters (or even
smats). Relaxation of the pelvic floor. $\downarrow$

Body map $\longrightarrow$ Feldenkrais 4 how diagonals in the nper body connect to the pelvic floor e.g. how the sternum move with the pelvic floor. Awareness of the pharynx,
diaphragm, and pelvic floor affect oneanother.

Body map

after

$\vdots$

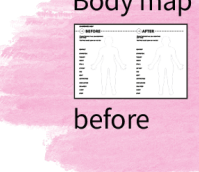

Body map

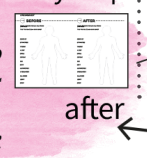

\section{$\equiv$ 'Sitting on a Chair'} awareness of how separate sides can be 'Lying down Tilting Knees to the Side'

\section{THE PELVIC CHAIR}

The Pelvic Chair is a furniture piece designed to create an awareness and understanding of your pelvis and pelvic floor area's connections and activation by using soft shape-changing elements. The chair subtly and slowly changes different areas of the seat around your pelvis and under your pelvic floor by increasing its volume and size, gently pushing you up a little bit. This draws your attention and awareness to your pelvic floor area. Through this you can make use and take support from your pelvic floor in other activities in life.

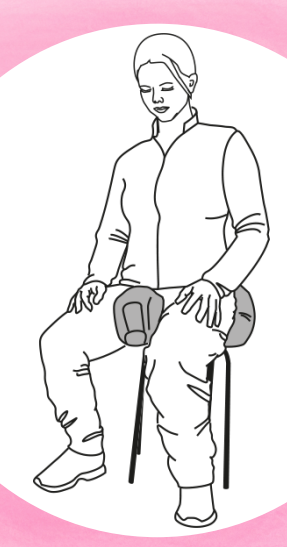

\section{ANCHOR POINT 2:}

transfer of experiential qualities from body maps

\section{FELDENKRAIS}

FLLEN alterna-

Feldenkrais explon our ways

tives of extending orld through

of being in the world move-

ments in alternative ways

$$
\text { ments in alternative ways }
$$
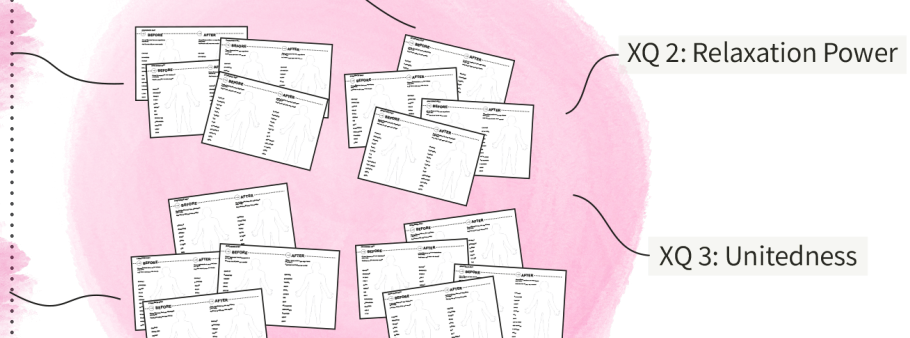

XQ 2: Relaxation Power

\section{$\mathrm{XQ}$ 1: Differentiation}

the ability to finely control different

parts of the pelvic floor, so that it is

not just perceived as one big chunk

front, a back, sides and everything in

between

XQ 4: Connectedness

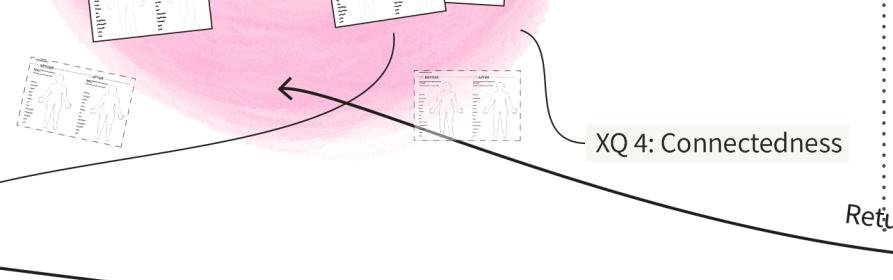

to Body Map
ANCHOR POINT 3:

Sketching with the

body \& materials

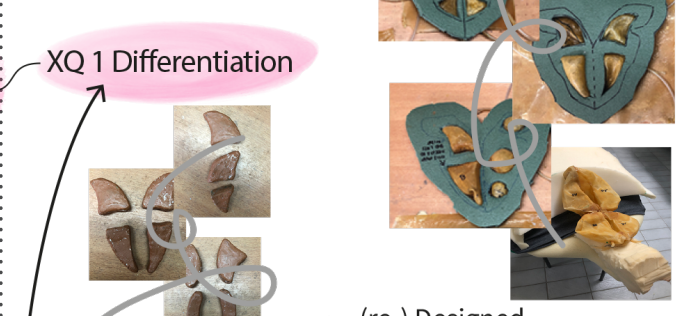

(re-) Designed experience

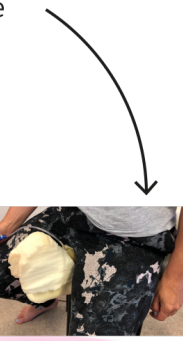

Recall Body Exercises 


\section{Body Maps in the Design Process}

Anchor Point 1, Tuning into the Soma

The design team of four designers used body maps as a way to capture the felt experiences in four instructor-led Feldenkrais lessons around the pelvis and the pelvic floor. They completed body maps before and after each session. All of them had previous experience of using body maps, which had turned out in successful designs [34, 35, 36, 40]. After completing the body maps, they shared their experiences within the group. In total the four lessons produced 16 body maps, examples to the right.

Body Maps in Anchor Point 2, Transfer to Experiential Qualities To extract experiential qualities, all body maps and notes taken were collected and used as a memory aid, to bring back the felt experiences. In the diagram on the previous page the quality 'Differentiation' was chosen as an example to illustrate how it links to the body maps. To the right here, details and quotes that led to the Differentiation quality are portrayed. The qualities aim to capture novel, reoccurring or extraordinary experiences around the pelvic area. The abstracted experiential qualities give the designers the freedom to not simply mirror the Feldenkrais lesson. They allow them to come up with new ideas and explore materials with other properties and affordances, but still guide them to stick with the original felt experiences.

Body Maps in Anchor Point 3, Sketching with the Body \& Materials Here the designers use their somas, their pelvises, to judge how their designed materials, in this case latex shapes pumped up with air, could hold 'Differentiation'. In an iterative manner they directly experienced the design prototypes, whilst returning to the guiding quality and the body maps to remember the original felt experiences. They let the somatic comparisons guide the design decisions. However this was not straightforward, given the evaluation takes place inside our somas, rather than a measurement on an external instrument. Given that only written words of a quality are inadequate, there is a need to bridge back to the felt experiences several times in order to more clearly discern the emergent interaction taking place between the body and a design object. For example, the designers had four large latex air shapes, when pumped up they could experience a direction, but not differences In the next iteration, guided by the quality and body maps, they discussed that it should be more of an indication, using smaller latex shapes. These iterations continued with fine adjustments until the design emerged that could convey the experience sought for. (Visualised to the right in the diagram on the previous page).

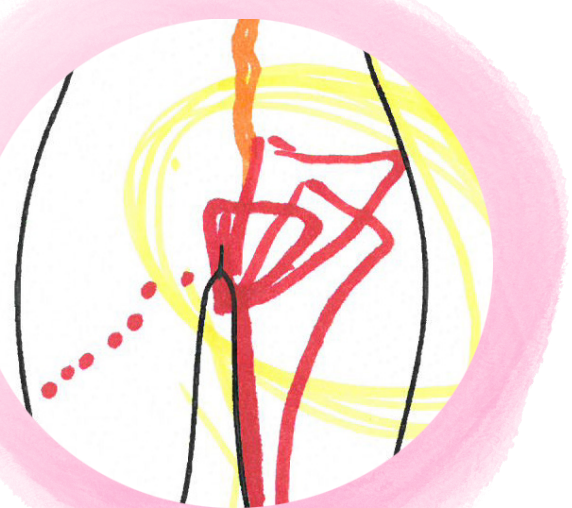

'I can clearly feel two separate parts, like a split diamond'

'Pelvic floor is bigger and more active on one side
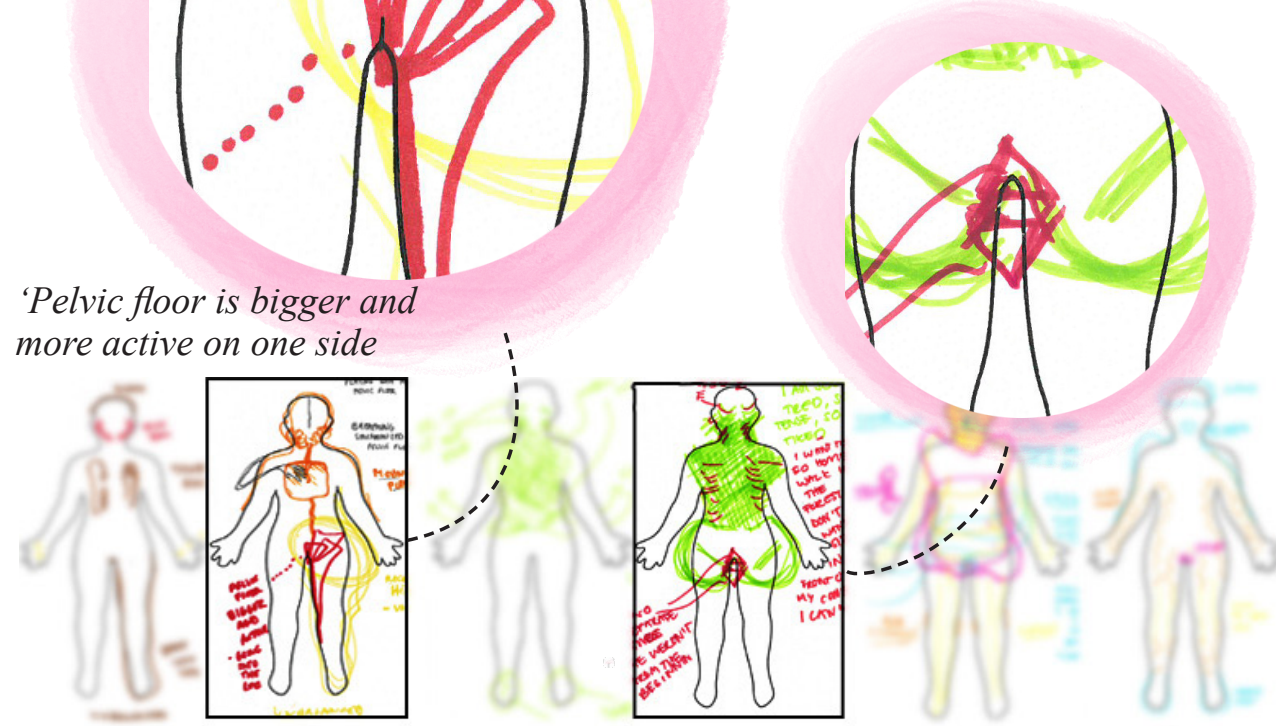

'Going to sides was hard'

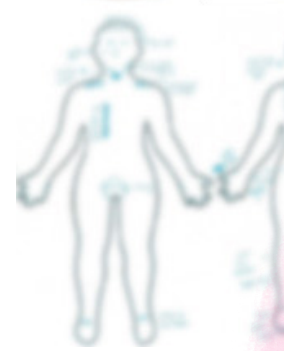

\section{'It is not all} damaged, much of itv is working.. awareness of the damage,*

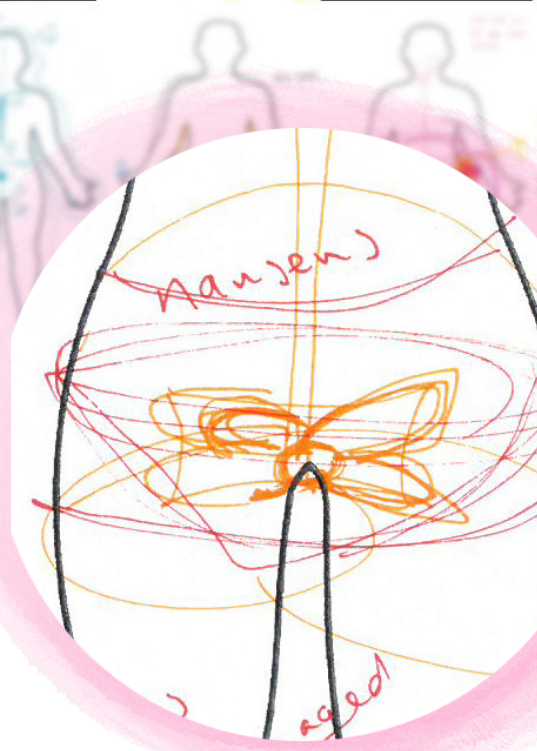

*one participant had a damage to the pelvic floor

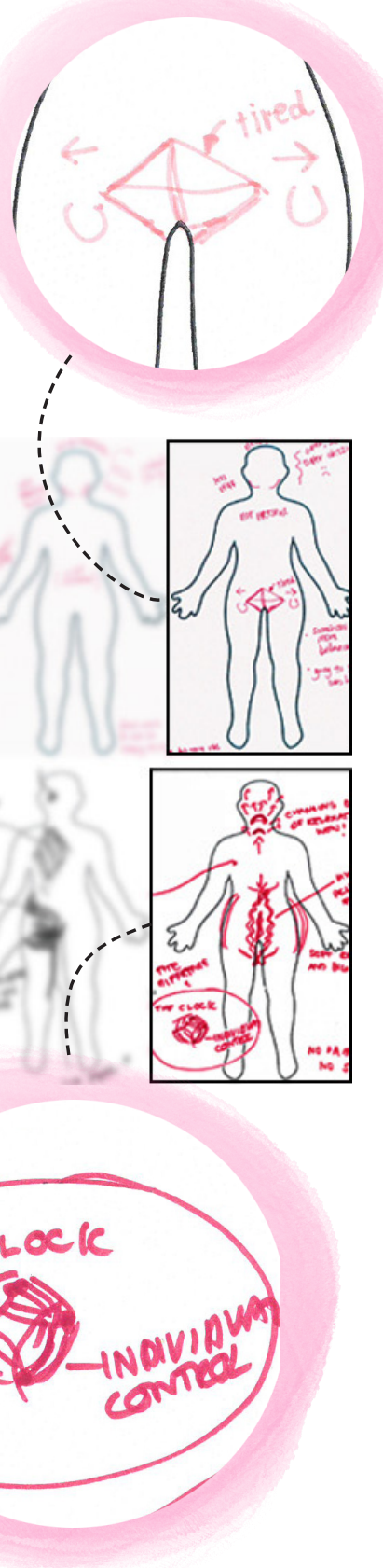




\section{CASE STUDY 2: UNDERSTANDING THE EXPERIENCE OF A GROUP WALKING MEDITATION EXERCISE}

Walking meditation is a mindfulness meditation exercise that uses the act of walking as a focus of attention to stay in the present moment [19]. With practicing walking meditation along with other mindfulness meditation exercises, the practitioners learn how to be more present in their lives which has positive benefits in their mental and physical wellbeing including emotional regulation and decrease of stress [8]. However, it can be difficult for practitioners, especially beginners to be able to articulate their experience during the practice. As designers, we need to understand the experience to inform our design decisions. Therefore, for this study, a qualitative workbook was designed for practitioners to fill out. Specifically, three body maps which represented specific points in the walking meditation practice were drawn after the session.

The body maps recorded in the workbook gave practitioners a visual representation of their experience before, during and after the walking meditation. For the purpose of this paper, the focus will be on the 3 final workshops developed in the study. In the workshops, practitioners used the system entitled Sound of Mind. Below, are examples of body maps of how the practitioners felt in the walking meditation. Practitioners drew these and edited them after the walking session, so as not to disrupt the walking meditation practice.

\section{SOUND OF MIND}

Sound of Mind is an interactive soundscape modulated by one practitioner's EEG data. More detailed information on the study can be found in the paper detailing the six workshops that use this method [5].

Walking Meditation Workshop Timeline

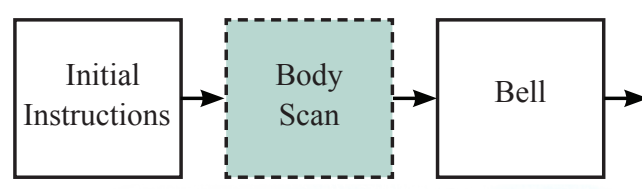

The intent of the research was to understand the experience of the practitioner while using the EEG modulated interactive soundscape. The researchers designed the self observation sections to specifically imprint the experience before, during and after the walking meditation practice so practitioners were then able to revisit the imprint of those self observation moments after the walking meditation was finished and draw their corresponding experiences on the body maps, highlighting significant sensations on body parts or annotating and drawing around the body to indicate other perceived feelings. The body maps were used as a prompt for participants to reflect on and share their experience. The maps then gave the researchers clues as to how the soundscapes were affecting the experience before, during and after the walking meditation.
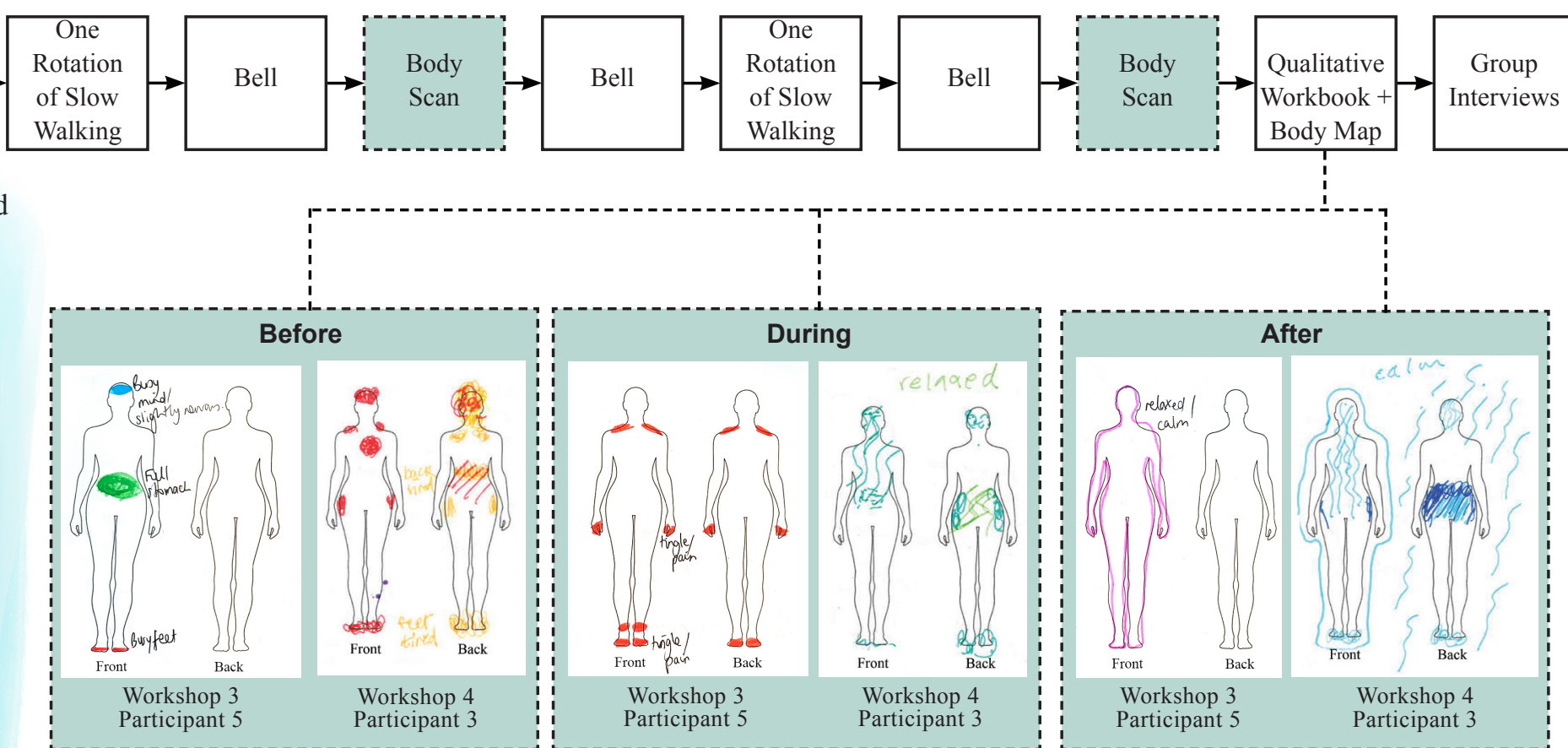


\section{Analysing the Body Maps}

After the workshops, the qualitative workbooks and the group interviews were analysed. To understand any emerging patterns from the body maps, the body maps were merged together into one diagram to see the frequency of the body parts reported before, during and after the walking meditation practice.

\section{Design Informed by the Body Maps}

For example, the soundscapes were originally designed to be loud at the beginning and quiet as the practitioners concentrated on the meditation practice. However, after analysing the body maps, practitioners noted that there were many bodily distractions (focus on the chest, stomach and feet) at the beginning of the practice. However, after their comfort level increased, their focus began to expand encompassing more of the environment. Therefore, the soundscape was changed to be quiet at the beginning of the experience and increased in volume as the practitioners moved towards a more meditative state.

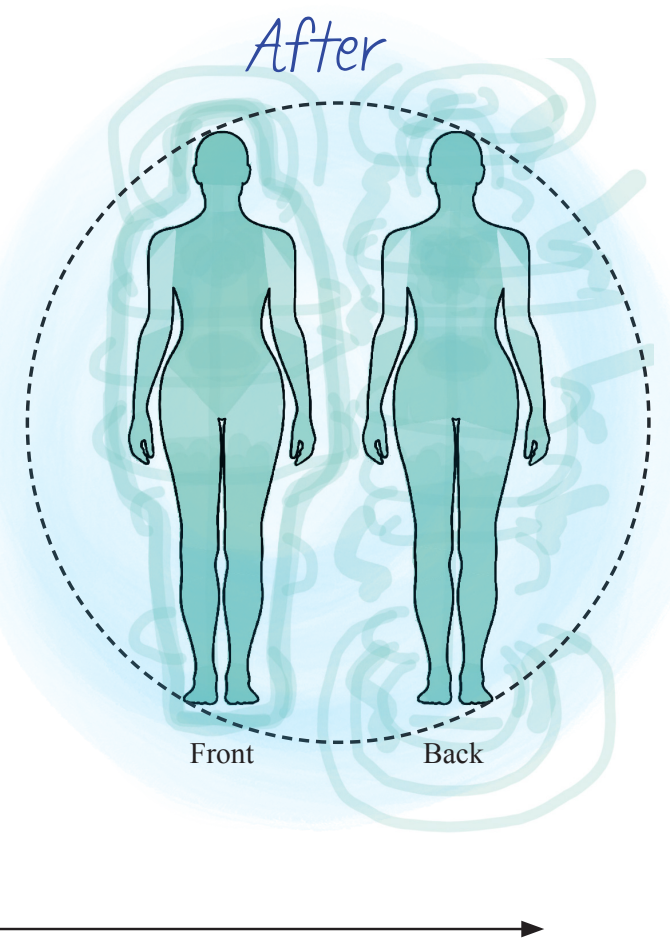

The timeline of the holistic experience with the colour indicidating the frequency of body parts reported on the body maps. 


\section{CASE STUDY 3: SELF-OBSERVATION OF}

\section{COMPASSION CULTIVATION FOR HCI}

In light of contemplative practice emerging as an area of research interest in $\mathrm{HCI}$, authentic descriptions of firstperson lived experience informing design in this area are few. This case presents a first-person self-observation study [26] of the lived experience of Tonglen [4], a Buddhist meditation technique for compassion cultivation. The researchers in this case study found that to keenly observe and document the embodied practice, it is important to go through preparatory stages of stabilising attention and observing the mind. For the researcher-cum-practitioner, the technique should be embedded into a framework training selfobservation and developing meta-awareness, supported by documentation of somatic snapshots and journal writing.

The protocol illustrated on the right, uses somatic snapshots [26] that function to sample experience at meaningful moments and support reflective observation of affective, cognitive and proprioceptive dimensions of experience. Kordes et al. define reflectively observing experience to mean "attending to experience precisely as it appears in the consciousness of the experiencing person" $[21, \mathrm{p} .6]$.

The experience was documented through postpractice journalling taking place within thirty minutes immediately after the Daily Practice. Body maps were used as a non-textual form of documentation of the practice and contemplative training to understand the dynamic unfolding experience of the body over time. Analysed in conjunction with written data, they represent a bridge to the tacit layers of experience. The study proposes that a researcher-cum-practitioner can develop and refine their sensitivity to capture somatic and kinaesthetic aspects of the unfolding and simultaneous processes with increasing granularity. The diagram on the right shows examples of body maps and excerpts from journaling that articulate the different foci of the Daily Practice.

\section{TONGLEN}

During Tonglen, the practitioner visualises taking the pain and suffering of others with every in-breath, and sending out whatever will benefit them in the form of light with the out-breath [4].

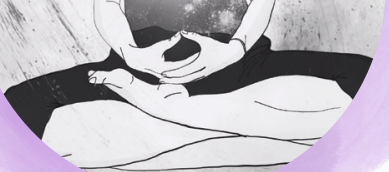

\section{Cultivation}

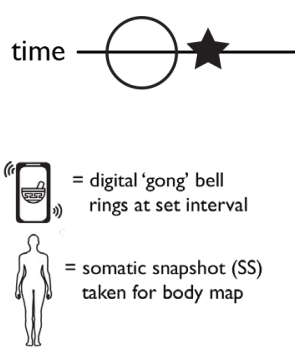

= a session of practice

= data collection
I. reflective writing 1. reflective writing/
audio recording 2. drawiong body maps
.

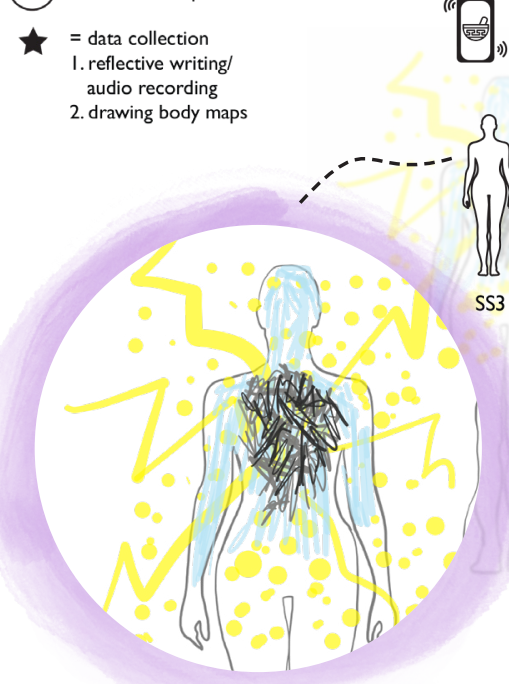
(1)
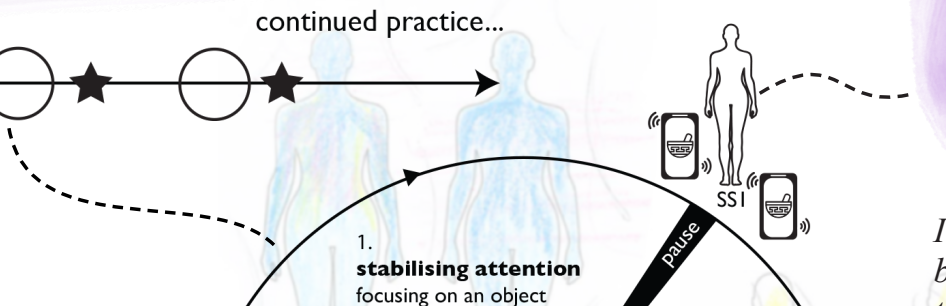

stabilising attention e.g. the breath
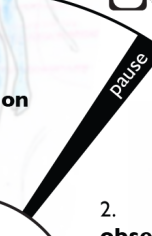

SSI
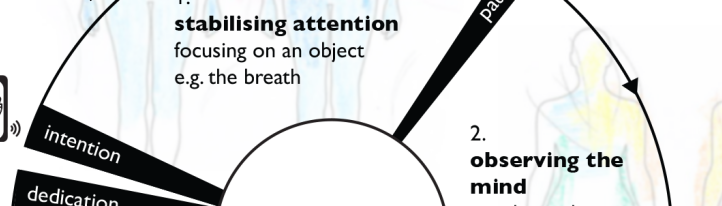

obse

the

mind

watching whatever

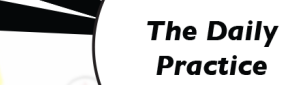

arises in the mind
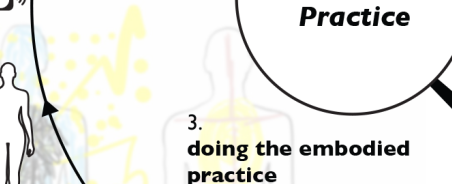

practice
e.g. Tonglen

SS3
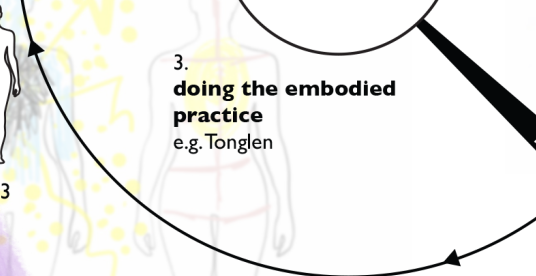

Something so hard, so

aggressive, and black, and

solid, can in an instant, diffuse into light. ... Recognition can be instantaneous... There is no process, but there is a process. How [something] can meet with one thing, and then completely change to softness.

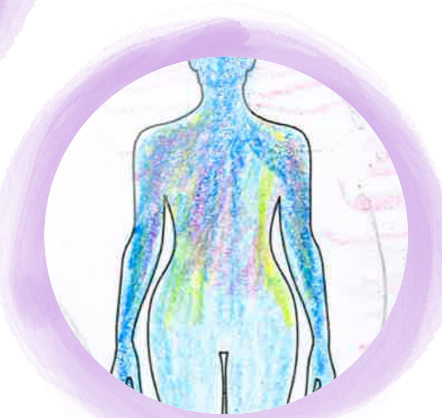

I felt time move across my body... I'm participating in this tapestry of noise. This tapestry of feeling. This tapestry of sight.
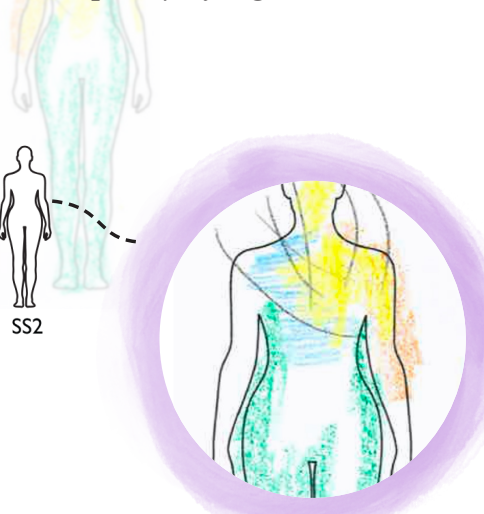

impermanence and movement, the flow of staleness being pushed out for the new. It doesn't have to be different, but it was always moving - material and immaterial - everything was moving... 
The researcher intends to generate a multi-dimensional reference of somatic memory of the practice [9] and knowledge, which would otherwise be invisible. The findings from the study aim to contribute towards understanding the quality of data that can be considered as intermediate-level knowledge [36] in the design context of contemplative practice and compassion cultivation. Using body maps to document the somatic snapshots fosters attunement of the researcher's selfawareness and inner dialogue. It gives multiple forms to the process of introspection while recognising simultaneously occuring mental and physical processes within the embodied practice over time.

\section{How are body maps used in the design research?}

The study proposes a systematic and rigorous approach for collecting first-person data to study a contemplative phenomenon that may ordinarily be difficult to articulate. The researchers iteratively developed their documentation protocol across three phases. During Phase 1, somatic snapshots were taken before, during and after the practice for data collection. However, as more clarity and distinction between the parts of the Daily Practice emerged, the somatic snapshots were re-positioned at more meaningful points of the practice. This clarified their function, which was to capture and represent the experiential qualities of each distinct focus of the contemplative training framework within the Daily Practice.

The contemplative framework for training selfobservation in HCI [26] reinforces the call for designers to develop our somatic sensibilities [23], extending this to observing cognitive activity through a more stable and vivid lens [39]. The researchers found that earlier body maps depicted more literal representations of the meditation technique, and over time, annotations became less prescriptive of the meditation instruction for Tonglen. Despite the study only being over twelve weeks, the researcher-cum-practitioner, experienced a familiarisation with the embodied practice of Tonglen and with their inner narrative that led to more nuanced somatic snapshots and increasing granularity and fidelity of markings. See below for examples.

The study presents a contemplative framework for training self-odservation to develop the researcher-cumpractitioner's sensitivity to their inner landscape. Thus, enabling them to navigate through abstract experiential qualities of nonlinear processes unfolding within an embodied cultivation practice. Systematic documentation of this process in multidimensional forms contributes to the rigour of interrogating of an experience from the firstperson perspective. In doing so, this approach generates a rich perspective and lexicon for a design context. In this way, first-person data can be a valuable resource for design practice and others in the field.
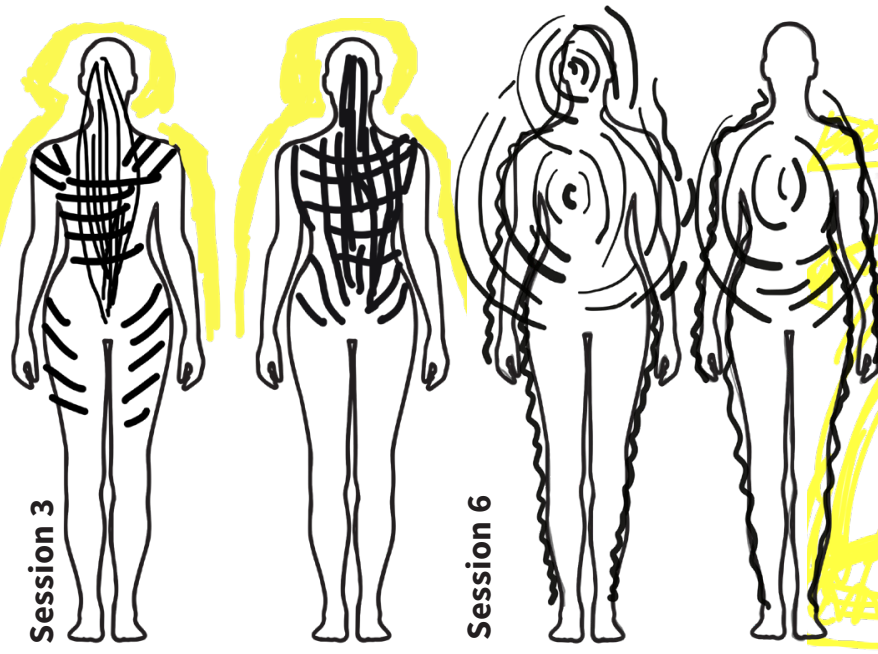

Back
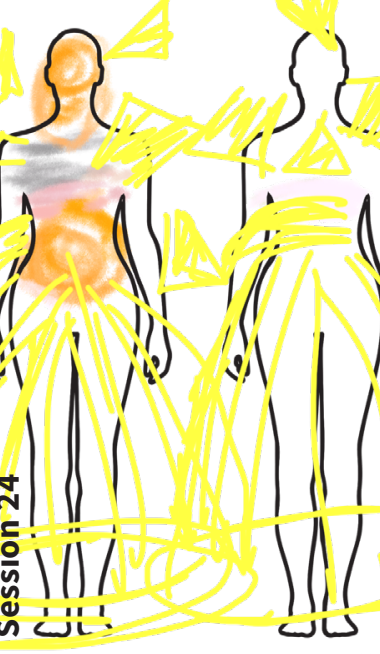

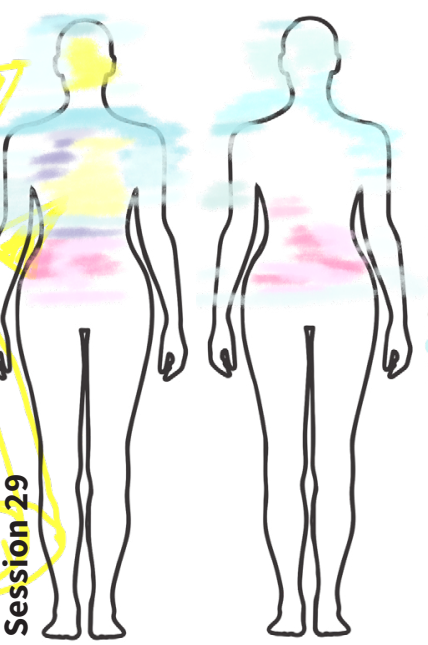

Body maps from Phase / of the study often reflected the meditation instruction more closely. There was also not much discrepancy between the front and back of the body.
Body maps from Phase 2 of the study illustrate an increased awareness of the dynamic somatic dimensions occuring during the practice.
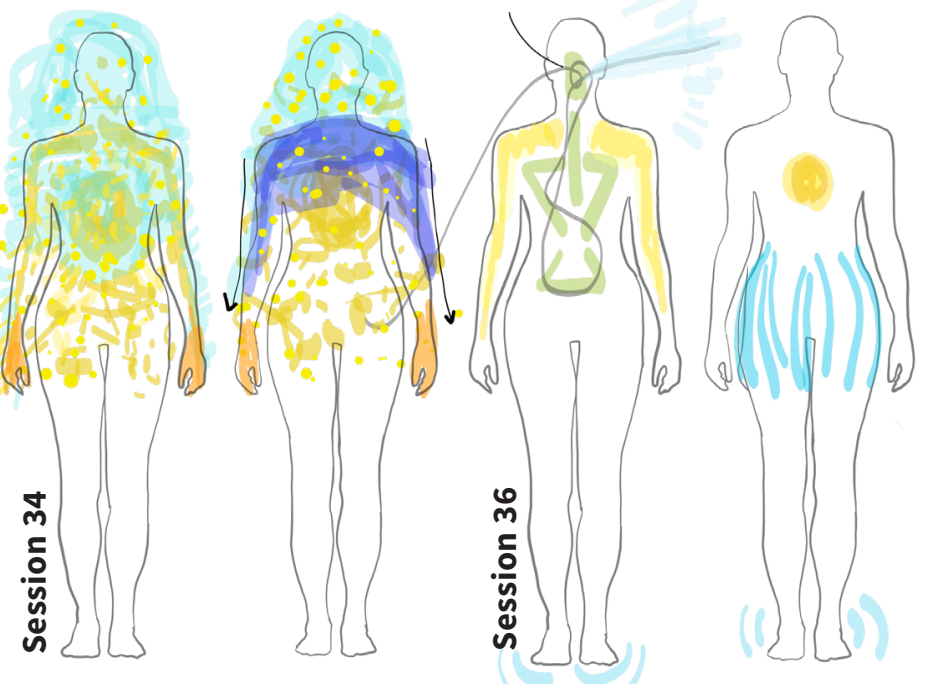

Body maps from Phase 3 of the study illustrate more granular elements of the somatic snaphot, increased discernment between the front and back body and specific and fine-grained markings representing multiple and simultaneously occuring processes. 


\section{CASE STUDY 4: THE FELT-SENSING ARCHETYPE} METHOD

Although body maps are by definition openended tools that value expressiveness, the way they were used in the final case study is relatively prescriptive. For this method, the researcher acts as a facilitator, assisting participants to connect with their bodies and emotions. Under that context, body mapping is used as part of a data analysis method called Felt-sensing Archetypes [28] (see next page), which intends to find patterns between written narratives and somatic experiences. This analytical instrument functions as part of a larger methodology, involving the use of the psychosomatic technique Focusing in the design process. Focusing is mostly used in psychology to connect embodied awareness to emotional situations to facilitate articulating experience in detail [14].

Body maps should highlight distinct sensations emerging during the exercises. In the workshops where this method is applied, participants are asked to focus on their bodies and identify a specific bodily state called "the felt-sense", The felt sense is generally perceived in the upper torso, making body maps slightly more succinct than other approaches. This succinctness, which still preserves the open-endedness that characterises body maps as projective tools, enables relatively straightforward traceability of response patterns in connection with texts and therefore opens the door forcoherent analysis

Traits described in Gendlin's phenomenological theory [14] of the felt-sense were used to find connections between the text and the body maps, giving form to the archetypes. In the design process, the felt-sensing archetype method has been used for data analysis towards defining aesthetic qualities inspiring design. This example does not aim to show the method exhaustively, but rather demonstrate how it is possible to find connections between narratives and body maps, despite the latter offering multiple interpretations.

\section{THE FELT-SENSE}

The felt-sense is our bodily awareness of concepts that are not yet articulated. It is a pre-linguistic sense of knowing something.

\section{CLOSE TO THE HEART}

A body map of before and after Focusing. On the left, we can see a body map that acknowledges different body parts, a common response to more open-ended bodyscanning sessions. On the other hand, the one on the right illustrates a very specific type of felt-sense-described in detail through the text as representing insolence tied to a strong sense of self.

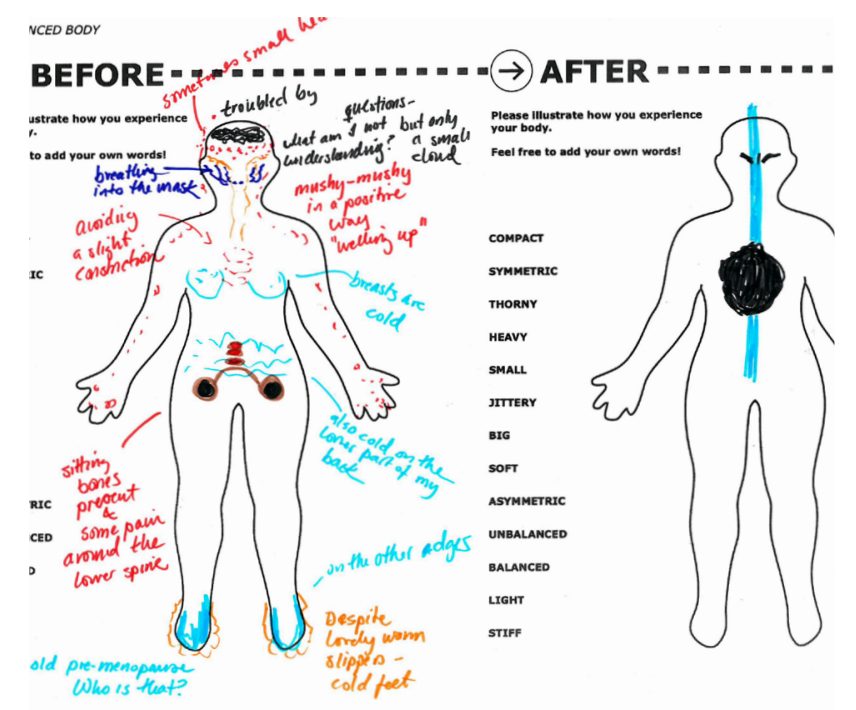

The felt sense is more strongly perceived in the trunk and throat, as the examples illustrated in the image. A body map that appears too diffuse generally indicates somatic disconnection, distraction or daydreaming.

Each answer sheet contains two body maps, for the front and the back of the body. The back is generally ignored, however in some cases, the felt sense can be perceived there (see example on next page).

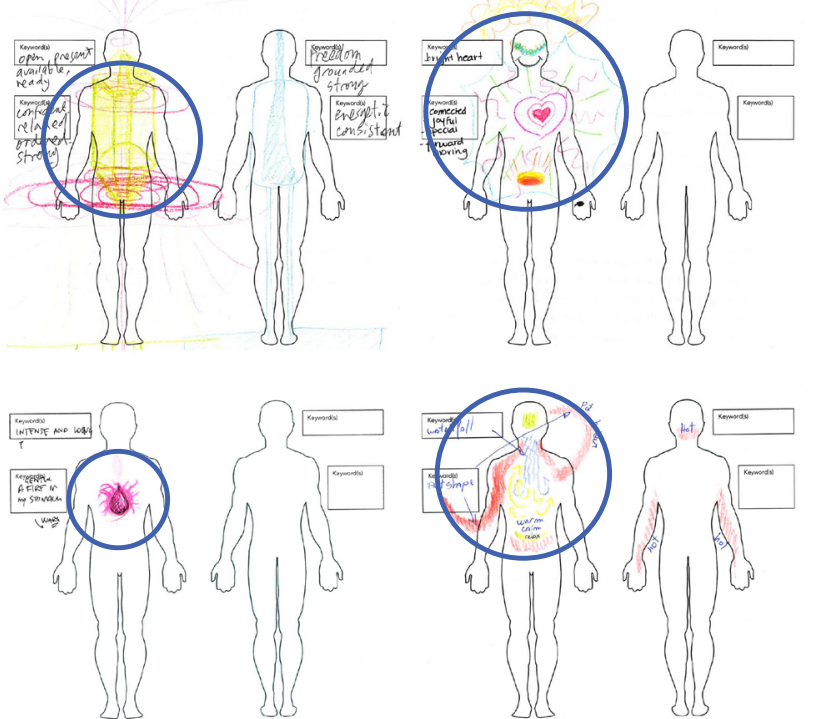




\section{Felt-sensing archetype patterns:}

This figure shows some exemplars corresponding to six felt-sensing archetypes, ranging from closer to or farther away from the felt-sense. These examples should be read in descending order, from narrative description to body map characteristics (see figure below). These patterns have been defined by analysing hundreds of narratives and their body maps through theory-driven categorisation. This example is intended for designers to inspire them to find their own patterns in the context of their own studies and methods. More details on this specific method can be found in [28].
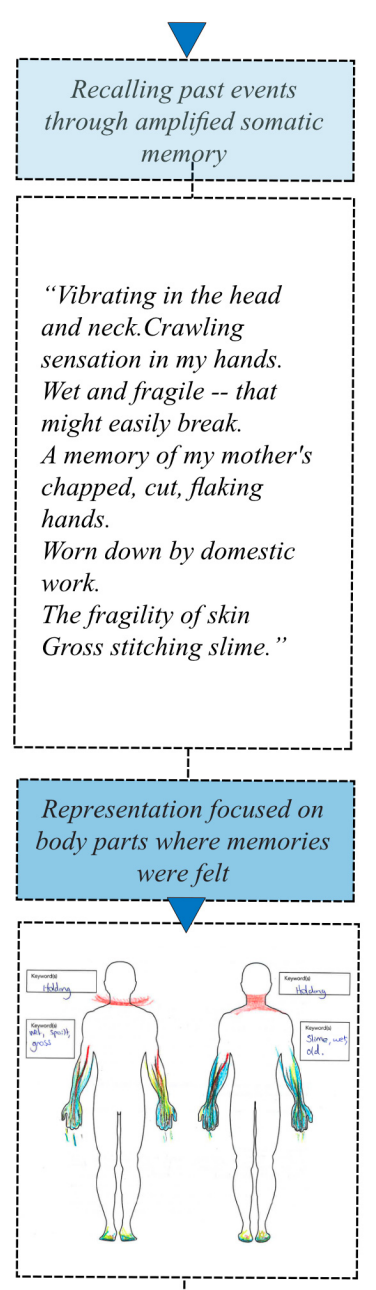

WRITER OF THE SELF [SOMATC]

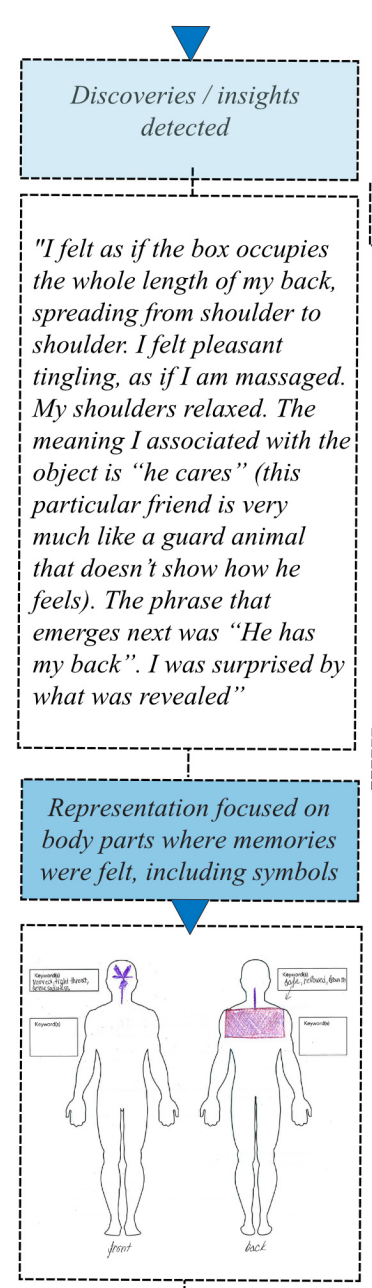

WRITER OF THE SELF [INSIGHT]

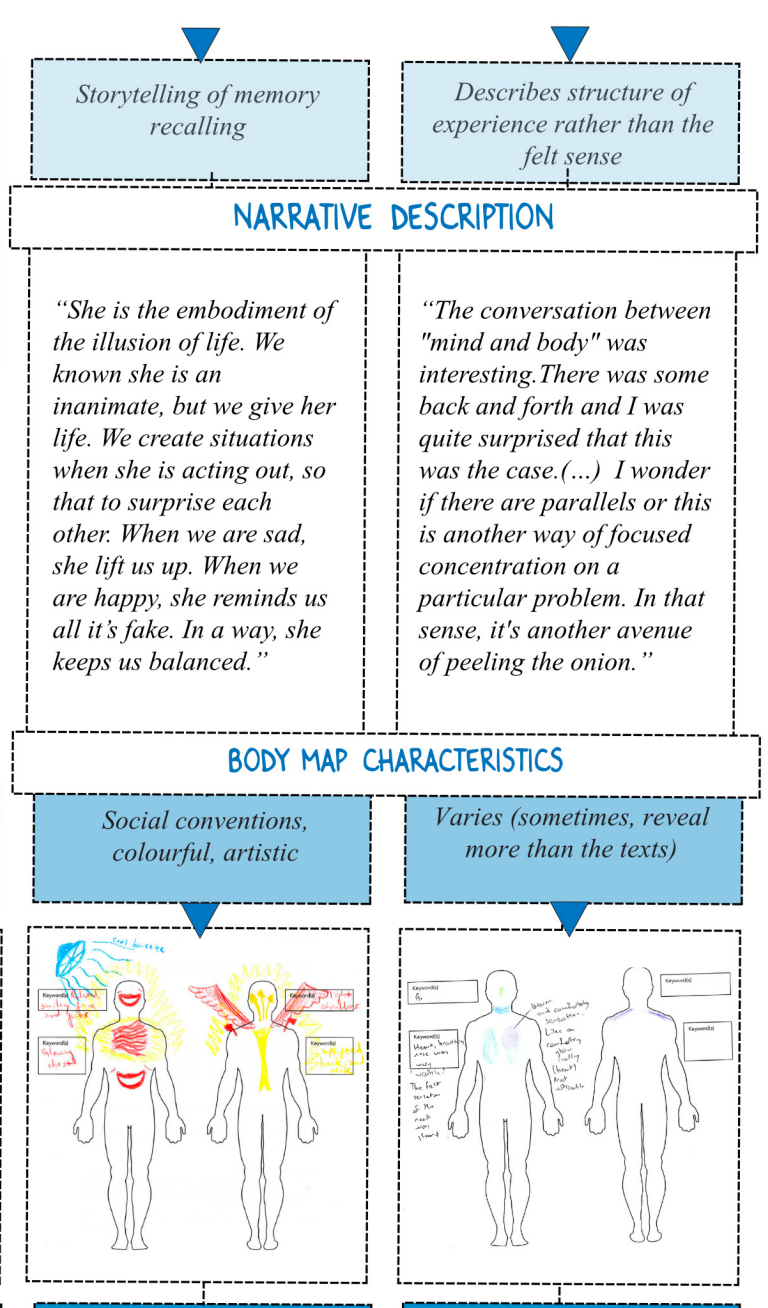

STORYTELLER

CONCEALER

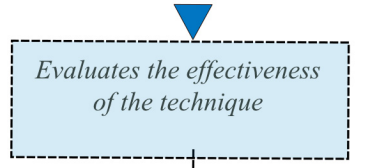

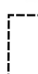

"Although I wasn't able to "focus" on the specific situation, I felt refreshed and energised to think the situation. So, I think the reflection might work after the exercise, but not during. Ok, it might work better after multiple times at doing it."
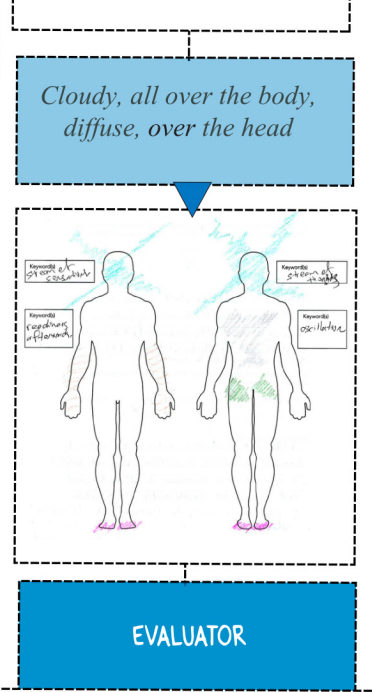

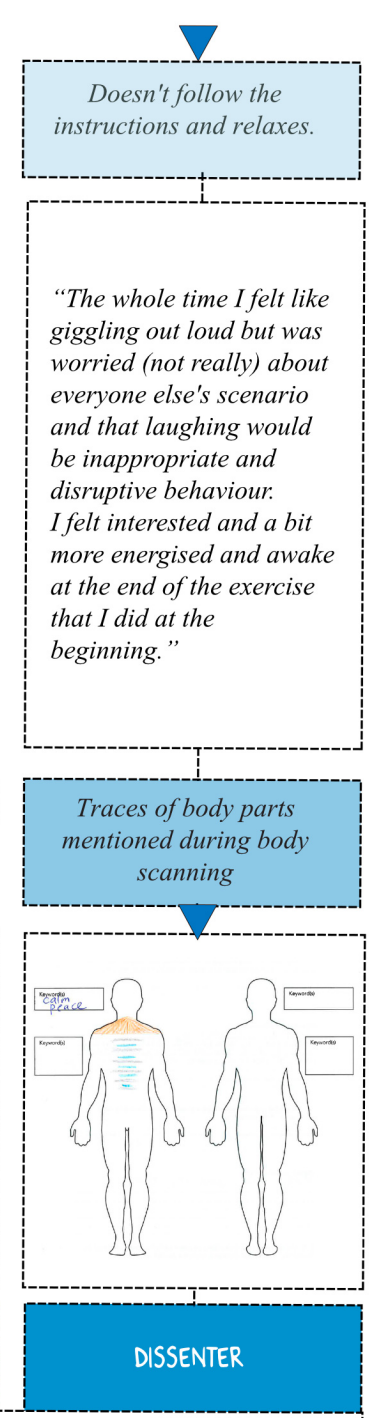

+ Farther to the felt-sense 


\section{BODY MAPS AS A GENERATIVE TOOL}

Body maps are open-ended and subjective, yet have a generative function. Generativity refers to the enabling capacity to facilitate exploration [31] and to create outcomes for research and practice, including new design ideas and knowledge. In our case studies, we illustrated how the body maps can become a generative tool in opening up many different forms of making use of the captured embodied and somatic experiences. We identify five uses of body maps:

1. Sample somatic experience: is similar to experience sampling [22], but with an explicit focus on bodily experience. It is the first step in observing the self and taking a somatic snapshot [17] of what is coming to awareness of one's bodily experience. All four case studies employ this use of body maps. Body maps can also be used with the sole purpose of creating body awareness before engaging in design activities, as in the guide on "how-to" provided in the pictorial, where there is no specific design activity included. This approach to body mapping as a sensitisation tool is commonly used in soma design workshops [3, 37].

\section{Foster heightened self awareness and inner dialogue:} the act of taking a somatic snapshot, of paying attention to inner experience and noticing what arises, especially when repeated over a prolonged period of time, will lead to a heightened self awareness. Depending on what techniques are practiced, an inner dialogue can produce new insights (the Focusing technique in case study 4) or self-transformation (compassion cultivation meditation technique in case study 3). Body maps are used to probe, trigger dialogue, document the experience, and provide a visual reference for self-reflection.

3. Understand the dynamic, evolving experience of the body over time: A series of body maps produced by a single person over a period of time can provide a data set that visualises how the body is experienced, and how the experience of the body changes over time (in case study 3 the researcher repeats the meditation practice; they do the same thing, yet the practice develops and refines their skill and self-awareness). The introduction of prototypes, materials and specific stimuli and the corresponding impact on bodily experience can be recorded and tracked through the body maps (in case study 1 the bodily experience of the pelvic chair and various prototypes are recorded on body maps, resulting in a somatic evaluation of the design).

4. Identify patterns of bodily experience: through analysis of a corpus of body maps collected from multiple participants, different kinds of patterns can be identified. In case study 2 , the body maps record each participant's experience of walking meditation. The set of body maps were visually analysed and combined with other written data to reveal how the somatic experience of a group of people is influenced by a rhythmic soundscape. The findings helped to inform design decisions to iterate the sonic prototype. Whereas in case study 4 , the set of body maps were analysed to produce a set of archetypes that capture the distinctive characteristics of how different people responded to the Focusing technique and its guidance on accessing the felt-sense of a situation.

5. Transfer bodily experiences via experiential qualities into a physical design: in a soma-based design process, body maps act as a projective tool in sampling and recording bodily experience. This is followed by a deliberate act of identifying experiential qualities from the body maps, which then guide the design work. In an iterative design process, there is a cycle of sampling bodily experience and recording on body maps, with generation and evaluation of prototypes. Case study 1 exemplifies this process.

An important distinction lies in whose bodily experience is recorded on a body map; that of the user or the designer/researcher. In our case studies we provided examples of first-person research by the designer/ researcher to document their own felt bodily experience (case study 1 and 3 ), versus inviting participants or users to document their experience (case study 2 and 4). The scaffolding required for using the body map will be different for these two groups. With users, often the study is a one-off, where they are invited to record their bodily experience on a body map immediately after going through an activity (e.g. walking meditation in case study 2 , felt-sensing in case study 4 ). The body map is one instrument of many in the data collection; users may share their experience with the researcher or group through conversation or writing. The researcher will then analyse the data to identify patterns of bodily experience [9], which may then inform design decisions $[5,40]$. In contrast, when designers/researchers use body maps to document their own bodily experience, they develop a familiarity with the tool as they refine their bodily awareness. A more complex, deeper understanding and documentation of somatic experience appears over a sustained period of time [26]. In an autobiographical design process, the body maps help chart the evolution of the design as informed by somatic design judgements grounded in bodily experience [34].

Body maps are just one way of capturing felt somatic experiences that might not be suitable for all designers and designs. It has its limitations; it does not capture the temporal details in an experience [36], but rather the somatic experiences that stand out, that you are/have become aware of. Bodymaps do not necessarily contain explicit information that can be easily interpreted or analysed; instead the data can be used for discussion and inspiration in design [5]. One should also be aware that body maps can bring out complex and non-explicit emotions and felt sensations, which might lead to unexpected emotions surfacing [2]. As an ethical consideration for workshops where body maps are shared, it is important to allow participants to keep their responses private if they feel uncomfortable speaking about their experiences through body mapping.

\section{CONCLUSION}

In the tradition of research-through-design, where the process of designing is valued as much as the product, we offer body maps as a generative tool for soma-based design. When designers or researchers use their own bodies, or ask participants to share felt bodily experiences, the use of body maps can provide a bridge between difficult to articulate tacit experience, somatic design judgments, and concrete design decisions. By illustrating a range of different possibilities offered by body maps, we aim to encourage design researchers to include and adapt these tools to fit the particularities of their design processes.

\section{ACKNOWLEDGMENT}

This work was supported and funded by the National Sciences and Engineering Research Council of Canada (NSERC) through a Discovery grant (2017-06300) and a Discovery Accelerator Supplement (2017-507935). 


\section{REFERENCES}

[1] Emilia Andersson and Gard Ove Sørvik. 2013. Reality lost? Re-use of qualitative data in classroom video studies. In Forum Qualitative Sozialforschung, Vol. 14 https://doi.org/10.17169/fqs $\{-\} 17.2 .2526$

[2] Madeline Balaam, Rob Comber, Rachel E Clarke, Charles Windlin, Anna Ståhl, Kristina Höök, and Geraldine Fitzpatrick. 2019. Emotion work in experiencecentered design. In Proceedings of the 2019 CHI Conference on Human Factors in Computing Systems. 1-12. https://doi.org/10.1145/3290605.3300832

[3] Madeline Balaam, Nadia Campo Woytuk, Marianela Ciolfi Felice, Ozgun Kilic Afsar, Anna Ståhl, and Marie Louise Juul Søndergaard. 2020. Intimate touch. interactions 27, 6 (2020), 14-17. https://doi.org/10.1145/3427781

[30] Claudia Daudén Roquet and Corina Sas. 2020. Body Matters: Exploration of the human body as a resource for the design of technologies for meditation. In Proceedings of the 2020 ACM Designing Interactive Systems Conference. 533546. https://doi.org/10.1145/3357236.3395499

[4] A. Berzin. 2020. Relative Bodhichitta and Tonglen. https://studybuddhism. $\mathrm{com} / \mathrm{en} / \mathrm{tibetanbuddhism/mind-training/commentaries-on-lojong-texts/}$ extensive-explanation-of-seven-point-mind-training-dr-berzin/relativebodhichittaand-tonglen

[5] Karen Cochrane, Lian Loke, Matthew Leete, Andrew Campbell, and Naseem Ahmadpour. 2021. Understanding the First Person Experience of Walking Mindfulness Meditation Facilitated by EEG Modulated Interactive Soundscape. In Proceedings of the Fifteenth International Conference on Tangible, Embedded, and Embodied Interaction. 1-17. https://doi.org/10.1145/3430524.3440637

[6] Bronwyne Coetze, Rizwana Roomaney, Nicola Willis, and Ashraf Kagee. 2019. Body Mapping in Research. Handbook of Research Methods in Health Social Sciences. $1237-1254$.

[7] Nigel Cross. 2001. Designerly ways of knowing: Design discipline versus design science. Design issues 17, 3 (2001), 49-55. https://doi.org/10.1007/1-84628-301-9

[8] D Davis and J Hayes. 2012. What are the benefits of mindfulness: A wealth of new research has explored this age-old practice. Here's a look at its benefits for both clients and psychologists. Monitor on Psychology 43 (2012), 198-208.

[9] Adèle De Jager, Anna Tewson, Bryn Ludlow, and Katherine Boydell. 2016. Embodied ways of storying the self: A systematic review of body-mapping. Form Qualitative Sozialforschung/Forum: Qualitative Social Research 17, 2 (2016). https://doi.org/10.17169/fqs-17.2.2526
[10] Dew, A., Collings, S., Senior, K., \& Smith, L. (2020). Applying Body Mapping In Research: An Arts-Based Method (K.M. Boydell, Ed.) (1st ed.). Routledge. https:// doi.org/10.4324/9780429340260

[11] Moshe Feldenkrais. 1972. Awareness through movement. Vol. 1977. New York: Harper and Row.

[12] Gastaldo, Denise; Rivas-Quarneti, Natalia \& Magalhães, Lilian (2018). BodyMap Storytelling as a Health Research Methodology: Blurred Lines Creating Clear Pictures [60 paragraphs]. Forum Qualitative Sozialforschung / Forum: Qualitative Social Research, 19(2), Art. 3, http://dx.doi.org/10.17169/fqs-19.2.2858.

[13] Bill Gaver and John Bowers. 2012. Annotated portfolios. interactions 19, 4 (2012), 40-49. https://doi.org/10.1145/2212877.2212889

[14] Eugene Gendlin. 1978. Focusing. Random House Digital, Inc.

[15] Kristina Höök. 2010. Transferring qualities from horseback riding to design. In Proceedings of the 6th Nordic Conference on Human-Computer Interaction: Extending Boundaries. 226-235. https://doi.org/10.1145/1868914.1868943

[16] Kristina Höök. 2018. Designing with the body: Somaesthetic interaction design. MIT Press.

[17] Kristina Höök and Jonas Löwgren. 2012. Strong concepts: Intermediate-level knowledge in interaction design research. ACM Transactions on Computer-Human Interaction (TOCHI) 19, 3 (2012), 1-18. https://doi.org/10.1145/2362364.2362371

[18] Katherine Isbister, Kristina Höök, Michael Sharp, and Jarmo Laaksolahti. 2006 The sensual evaluation instrument: developing an affective evaluation tool. In Proceedings of the SIGCHI conference on Human Factors in computing systems. 1163-1172. https://doi.org/10.1145/1124772.1124946

[19] Jon Kabat-Zinn. 2018. Falling awake: how to practice mindfulness in everyday life. Hachette UK.

[20] George Knut. 2016. Designing biofeedback artworks for relaxation. In Proceedings of the 2016 CHI Conference Extended Abstracts on Human Factors in Computing Systems. 3859 - 3862. http://doi.org/10.1145/2851581.2891089

[21] Urban Kordeš and Ema Demšar. 2021. Being there when it happens: A novel approach to sampling reflectively observed experience. New Ideas in Psychology 60 (2021), 100821.

[22] Larson, R., Csikszentmihalyi, M. (1983). "The experience sampling method". New Directions for Methodology of Social and Behavioral Science, 15, 41-56. 
[23] Lian Loke and Claudia Núñez-Pacheco. 2018. Developing somatic sensibilities for practices of discernment in interaction design. The Senses and Society 13, 2 (2018), 219-231.

[24] Lian Loke and Thecla Schiphorst. 2018. The somatic turn in human-computer interaction. Interactions 25, 5 (2018), 54-5863. https://doi.org/10.1145/3236675

[25] Jonas Löwgren. 2007. Pliability As An Experiential Quality: Exploring The Aesthetics Of Interaction Design. Artifact 1, 2 (2007), 85-95. https: //doi. org/10.1080/17493460600976165

[26] Kristina Mah, Lian Loke, and Luke Hespanhol. 2021. Towards a contemplative research framework for training self-observation in HCI: A Study of Compassion Cultivation. In ACM Transactions on Computer-Human Interaction (TOCHI). https://doi.org/10.1145/3471932

[27] Harold G Nelson and Erik Stolterman. 2014. The design way: Intentional change in an unpredictable world. MIT press.

[28] Núñez-Pacheco, C. (2021, February). Tangible Body Maps of Felt-Sensing Experience. In Proceedings of the Fifteenth International Conference on Tangible, Embedded, and Embodied Interaction (pp. 1-3). https://doi. org/10.1145/3430524.3442700

[29] Claudia Núñez-Pacheco and Lian Loke. 2016. Felt-sensing archetypes: Analysing patterns of accessing tacit meaning in design. In Proceedings of the 28th Australian Conference on Computer-Human Interaction. 462-471. https://doi. org/10.1145/3010915.3010932

[31] Sanders E.BN. (2000) Generative Tools for Co-designing. In: Scrivener S.A.R., Ball L.J., Woodcock A. (eds) Collaborative Design. Springer, London

[32] Donald A Schön. 2017. The reflective practitioner: How professionals think in action. Routledge.

[33] Louisa Smith. 2020. Applying Body Mapping In Research: An Arts-Based Method. (2020). https://doi.org/10.4324/9780429340260

[34] Anna Ståhl, Martin Jonsson, Johanna Mercurio, Anna Karlsson, Kristina Höök, and Eva-Carin Banka Johnson. 2016. The soma mat and breathing light. In Proceedings of the 2016 CHI Conference Extended Abstracts on Human Factors in Computing Systems. 305-308. https://doi.org/10.1145/ 2851581.2889464

[35] Anna Ståhl, Vasiliki Tsaknaki, and Madeline Balaam. 2021. Validity and Rigour in Soma Design - Sketching with the Soma. ACM Transactions on ComputerHuman Interaction (TOCHI), 28:6, Special Issue on First-Person Research in HCI 